
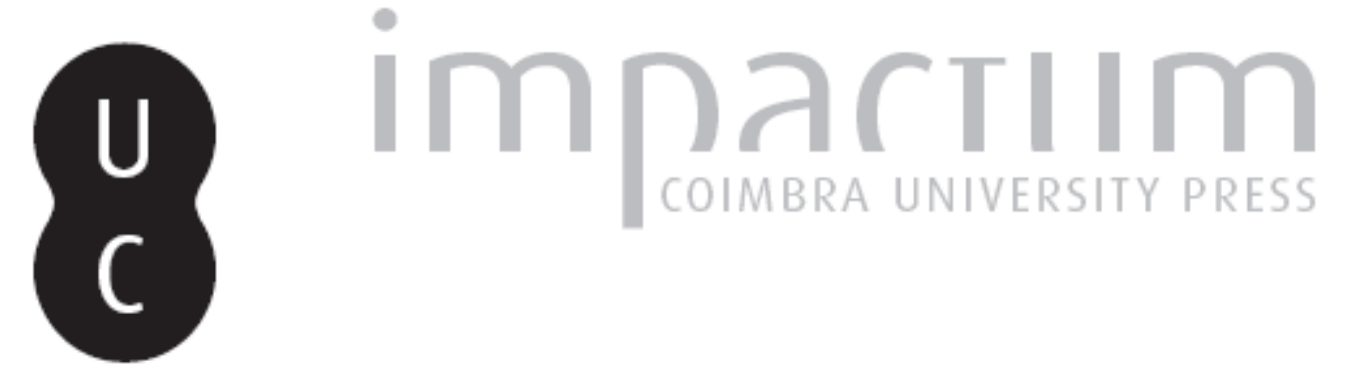

\title{
Influência das condições climáticas na qualidade do vinho da sub-região vitivinícola de Castelo Rodrigo (1992-2012)
}

Autor(es): $\quad$ Maia, Maria Manuela Lourenço; Nunes, Adélia de Jesus Nobre

Publicado por: Imprensa da Universidade de Coimbra

URL persistente:

URI:http://hdl.handle.net/10316.2/36883

DOI:

DOI:http://dx.doi.org/10.14195/0871-1623_33_3

Accessed : $\quad$ 26-Apr-2023 04:43:18

A navegação consulta e descarregamento dos títulos inseridos nas Bibliotecas Digitais UC Digitalis, UC Pombalina e UC Impactum, pressupõem a aceitação plena e sem reservas dos Termos e Condições de Uso destas Bibliotecas Digitais, disponíveis em https://digitalis.uc.pt/pt-pt/termos.

Conforme exposto nos referidos Termos e Condições de Uso, o descarregamento de títulos de acesso restrito requer uma licença válida de autorização devendo o utilizador aceder ao(s) documento(s) a partir de um endereço de IP da instituição detentora da supramencionada licença.

Ao utilizador é apenas permitido o descarregamento para uso pessoal, pelo que o emprego do(s) título(s) descarregado(s) para outro fim, designadamente comercial, carece de autorização do respetivo autor ou editor da obra.

Na medida em que todas as obras da UC Digitalis se encontram protegidas pelo Código do Direito de Autor e Direitos Conexos e demais legislação aplicável, toda a cópia, parcial ou total, deste documento, nos casos em que é legalmente admitida, deverá conter ou fazer-se acompanhar por este aviso.

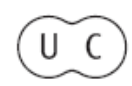




\section{Cadernos de Geografia}
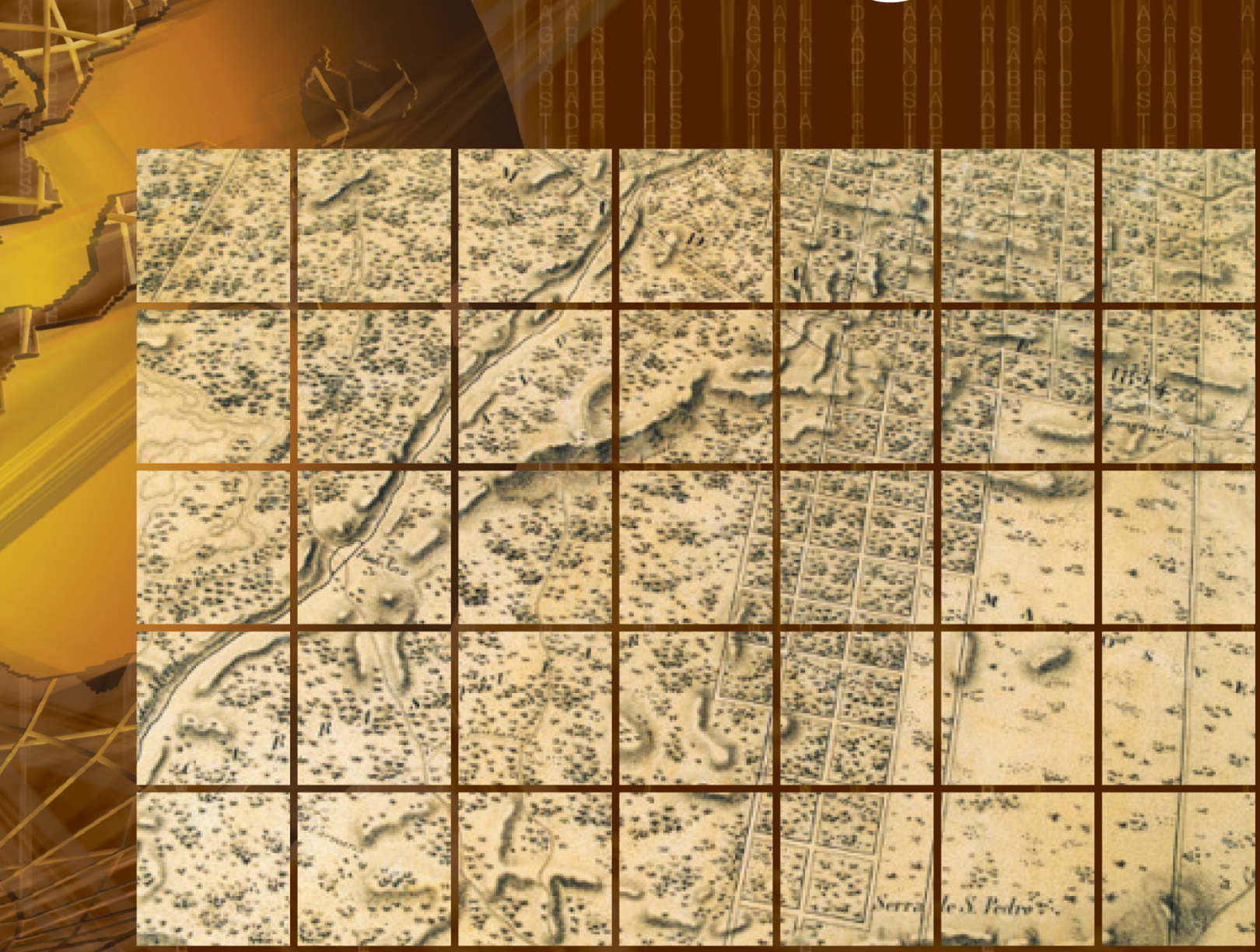

№ 33 - 2014

Imprensa da Universidade de Coimbra Faculdade de Letras | Universidade de Coimbra 


\title{
Influência das condições climáticas na qualidade do vinho da sub-região vitivinícola de Castelo Rodrigo (1992-2012) ${ }^{1}$ Influence of climatic conditions on the quality of the wine in the sub-region of Castelo Rodrigo (1992-2012)
}

\author{
Maria Manuela Lourenço Maia \\ Faculdade de Letras, Universidade de Coimbra. \\ maria_maia90@hotmail.
}

\section{Adélia de Jesus Nobre Nunes}

Faculdade de Letras, Universidade de Coimbra. adelia.nunes@fl.uc.pt.

\section{Resumo:}

O presente trabalho pretende avaliar a influência das condições climáticas (em particular da temperatura e da precipitação) na qualidade dos mostos produzidos na sub-região de Castelo Rodrigo, no período de 1992 a 2012. Para o efeito, além da análise de correlações entre a temperatura (média, mínima e máxima) e a precipitação total, no período correspondente ao ciclo vegetativo da videira (1 de Abril a 30 de Setembro), foram definidos 3 índices climáticos vitícolas: Índice Heliotérmico, Índice de Frio Noturno e o Índice Branas, Bemon e Lavadoux (IBBL)

Os resultados obtidos mostram que a qualidade dos mostos têm vindo a aumentar nestes últimos 20 anos, nesta sub-região vinícola, traduzida no incremento do grau dos mostos, de algumas das castas mais importantes na área. Este incremento na qualidade dos mostos relaciona-se, de modo positivo, com as temperaturas médias e máximas mensais e com o índice heliotérmico. Com uma correlação negativa destacam-se os quantitativos de precipitação registados no decurso do período vegetativo da videira.

Com efeito, no decurso do período analisado, verificou-se uma tendência de incremento nas temperaturas máximas e médias e, por conseguinte, nos valores do índice heliotérmico. Com tendência negativa destacam-se os quantitativos de precipitação registados no período de 1 de Abril a 30 de Setembro. A conjugação destas tendências reverteu a favor do aumento da qualidade dos mostos e também da antecipação da data de colheita. Contudo, serão ainda abordados outros fatores que interferem na qualidade dos vinhos.

Palavras-chave: Influência Climática. Qualidade dos mostos. Castelo Rodrigo. Portugal.

\section{Abstract:}

This study aims to assess the influence of climatic conditions (particularly temperature and precipitation) in the quality of the musts produced within the sub - region of Castelo Rodrigo, between 1992 and 2012. To this purpose, besides the analysis of correlations between temperature (mean, minimum and maximum) and the total of precipitation during the vegetative cycle of the vine (1 April to 30 September), other 3 viticultural climate indices are defined: the Heliothermal index, the Cool Night Index and the Branes, Bemon and Lavadoux index (IBBL).

The results show that the quality of musts has been increasing in this wine sub-region, over the last 20 years, reflected in the increase of the degree of the musts, particularly in the most important varieties in the area. This increase in the quality of musts relates, positively, with the mean and maximum monthly temperatures and with the heliothermic index. With a negative correlation highlight the quantitative precipitation recorded during the growing season of the vine.

In fact, during the analyzed period there was a positive trend in maximum and mean temperatures and, therefore, in the heliothermic index. With negative trend highlight the quantitative rainfall registered during the period 1 April to 30 September. The combination of these trends has reversed in favor of increasing of the quality of musts as well as in anticipation of harvest date. However, other factors that affect the quality of the wines will also be discussed.

Keywords: Climate Influence. Quality of the musts. Castelo Rodrigo. Portugal.

\footnotetext{
Este trabalho corresponde à comunicação, com o mesmo título, apresentada no VIII Colóquio de Geografia de Coimbra, subordinado ao tema "Espaço, Natureza e Sociedade. A Geografia na Estratégia 2020 da Região Centro", realizado na Faculdade de Letras da Universidade de Coimbra, nos dias 27 e 28 de março de 2014
} 


\section{Introdução}

A Vitis vinifera (L.) é uma planta pertencente à família das vitáceas, sendo o seu nome vulgar videira ou videira europeia. Vários autores consideram que as condições climáticas intervêm fortemente no desenvolvimento e produtividade da vinha, bem como na qualidade da produção (NunEs \& VIEIRA, 1999; Tonietto, J. \& Carbonneau, A., 1999; Oliveira, 2000; MACHADO et al., 2010; Nilson et al., 2010; Lourenzo et al., 2012; Monteiro et al., 2012). Com o presente trabalho pretende descortinar a influência que as condições climáticas, nomeadamente a temperatura e a precipitação, registadas na sub-região de Castelo Rodrigo, no período compreendido entre 1992 a 2012, exerceram na qualidade final dos mostos, traduzida pelo grau alcançado. A sub-região de Castelo Rodrigo integra-se na Denominação de Origem Beira Interior, criada em 1999, em resultado da aglutinação desta região com as da Cova da Beira e Pinhel.

Sendo o foco principal deste estudo compreender de que forma as condições climáticas atuam na qualidade vitivinícola, os objetivos de investigação vão passar, numa fase inicial, pela análise climática da área de estudo (interpretando a evolução das temperaturas e precipitação, assim como, a análise ao respetivo potencial climático, através do cálculo de índices climáticos) e, numa segunda fase, pela avaliação dos resultados enológicos alcançados (analisando a evolução da qualidade vitivinícola e a influência que a temperatura e precipitação exercem na qualidade e determinação da data de colheita).

\section{Materiais e métodos}

\section{1. Área de estudo}

A sub-região vitivinícola de Castelo Rodrigo localiza-se no extremo Nordeste da Beira Interior Norte, entre os vales dos rios Côa e Águeda, entre $40^{\circ} 35^{\prime}$ e $40^{\circ} 59^{\prime} \mathrm{N}$ de latitude e aos $6^{\circ} 47^{\prime}$ e $7^{\circ} 8^{\prime} \mathrm{O}$ de longitude (Figura 1 ). Fazem parte desta sub-região, os concelhos de Figueira de Castelo Rodrigo (expecto a freguesia de Escalhão) e parte de Almeida (freguesias de Almeida, Castelo Bom, Junça, Malpartida e Naves). Ocupa uma área total de $563 \mathrm{~km}^{2}$. A sub-região insere-se numa superfície aplanada, a qual pertence à Meseta Ibérica (unidade de relevo mais antiga da Península Ibérica), da qual a serra da Marofa se distingue como um relevo de imponente forma, alcançando a sua cota máxima aos $977 \mathrm{~m}$, assumindo uma orientação Este/Oeste. As vinhas plantadas na sub-região encontram-se a uma altitude que varia entre os 500 e os 700 metros.

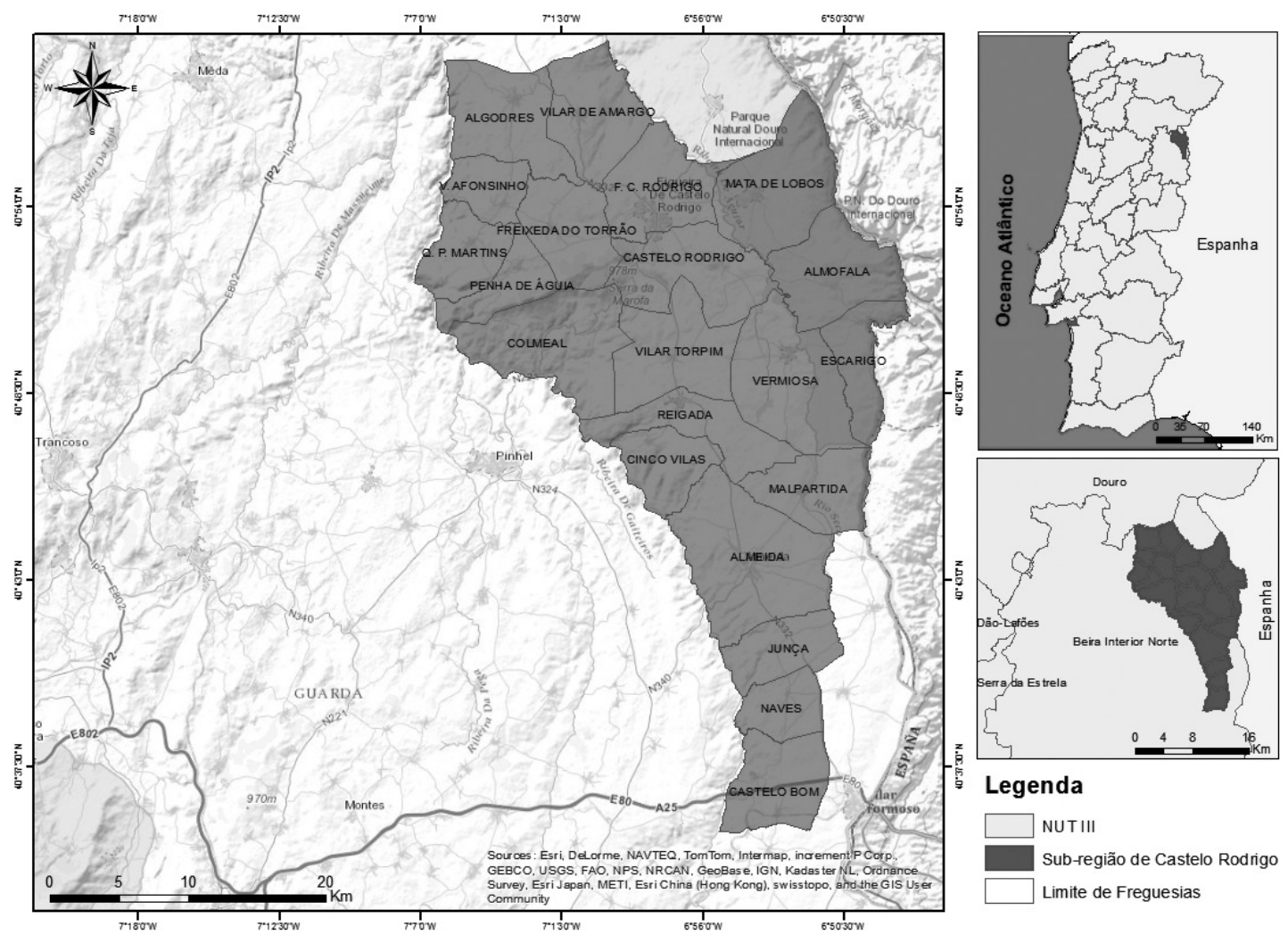

Figura 1

Enquadramento geográfico da sub-região de Castelo Rodrigo.

Fonte: Elaborado a partir de dados da Carta Administrativa Oficial de Portugal (CAOP-2012.1), IGOE. 
Na sub-região de Castelo Rodrigo registam-se em média $590 \mathrm{~mm}$ ano de precipitação, a temperatura média anual ronda os $13^{\circ} \mathrm{C}$ e a evapotranspiração potencial atinge os $700 \mathrm{~mm} /$ ano. A estação estival, segundo o índice de Gaussen, dura em média 3 meses (Figura 2). De acordo com a classificação de Rivas- Martínez (1996), é um território Mesomediterrâneo superior, sub-húmido inferior com um índice de aridez bastante acentuada.

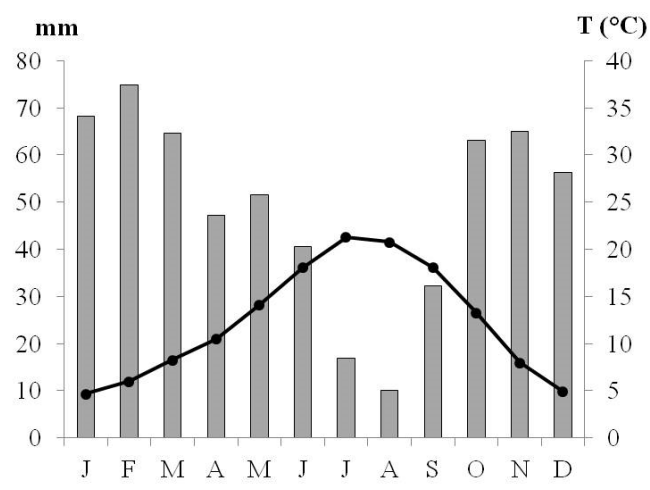

Figura 2

Temperatura e precipitação média mensal em Castelo Rodrigo (1951-1980) Fonte: Instituto Nacional de Meteorologia e Geofísica
A sub-região é constituída a Norte e a Sul por rochas granitóides, enquanto na parte central dominam rochas do complexo xisto-grauváquico. Distinguem-se, do ponto de vista pedológico, três unidades principais: cambissolos, litossolos e luvissolos (Figura 3). Os litossolos êutricos são solos incipientes que não apresentam diferenciação de perfil, a presença de horizontes orgânicos não se verifica nestes solos ou de qualquer outro vestígio de processos dinâmicos ao longo do seu perfil. Apresentam pH superior a 5,5 e não contêm carbonatos no perfil. Os cambissolos, considerados como solos mais ricos, são pouco evoluídos, apresentando uma leve diferenciação de horizontes. Estes solos são constituídos por material mineral, contendo um horizonte B incipiente. A sequência de horizontes é composta da seguinte forma: horizonte A ou Hístico, Bi, C, com ou sem R. Dentro desta unidade pedológica surgem três sub-unidades na nossa sub-região: os cambissolos êutricos, os cambissolos húmicos e os cambissolos distrícos. Os luvissolos órticos são solos evoluídos, surgindo este território associado a Unidades Alóctones não Diferenciadas e Cascalheiras de Planalto da Beira Baixa. Estes solos apresentam uma clara diferenciação de horizontes, manifestando processos dinâmicos verticais ao longo do seu perfil importantes, o que leva à formação de um horizonte $B$ argílico (horizonte iluvial com acumulação apreciável de argilas). Oferecem uma tonalidade vermelha, o que os leva à designação de solos mediterrâneos vermelhos.

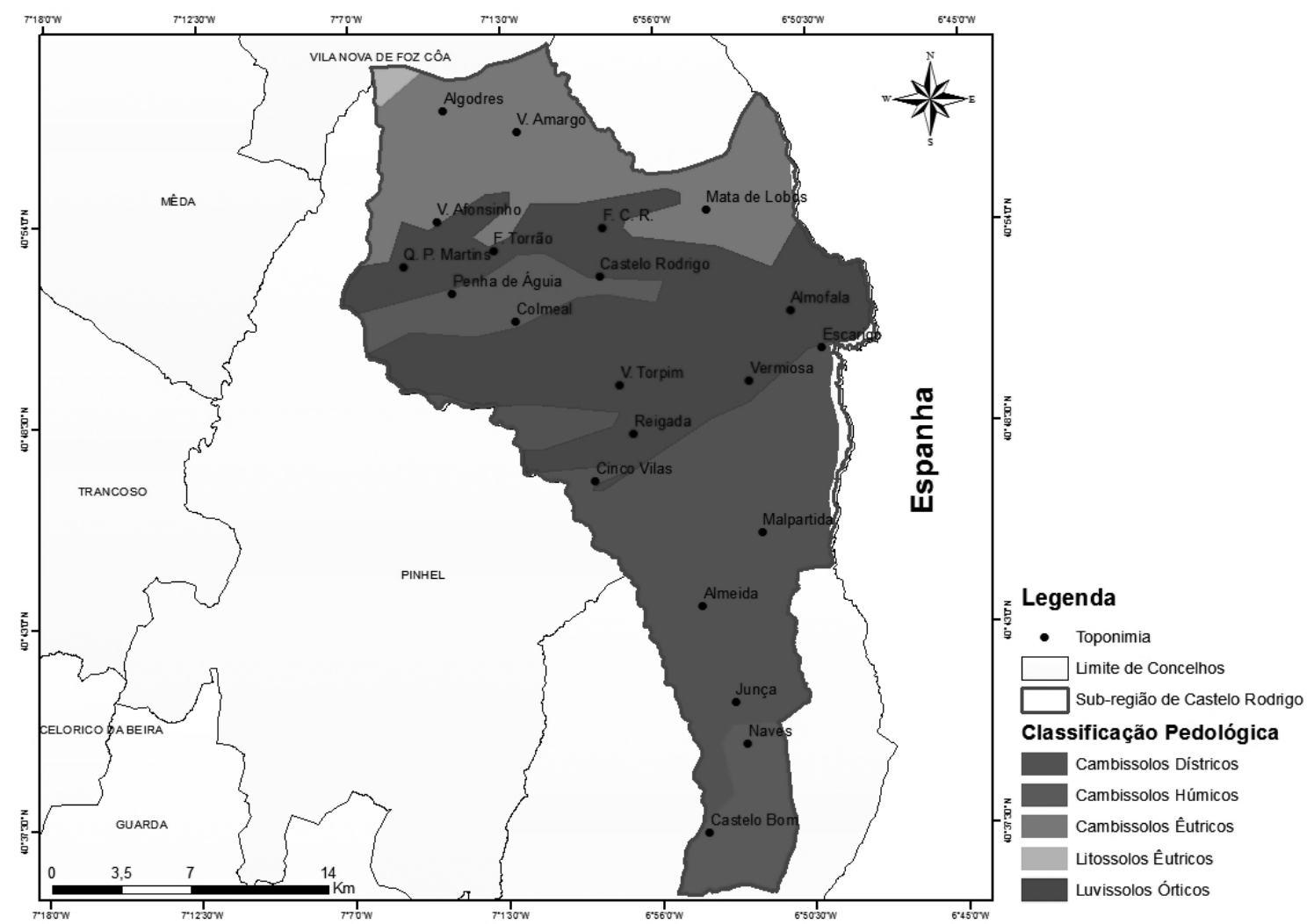

Figura 3

Unidades Pedológicas da Sub-região de Castelo Rodrigo.

Fonte: Elaborado a partir de dados disponíveis no Atlas do Ambiente. 


\subsection{Recolha e análise dos dados}

Os dados referentes à qualidade dos mostos, entre 1992 e 2012, foram cedidos pela Adega Cooperativa de Figueira de Castelo Rodrigo, assim como a data de início da colheita. No que se refere às variáveis climáticas, os dados relativos à evolução das temperaturas e precipitação, durante as duas décadas em estudos, restringiram-se ao período compreendido entre o dia 1 de Abril e 30 de Setembro, uma vez que é neste intervalo de tempo que ocorre o período ativo do ciclo vegetativo da videira.

Os dados foram recolhidos nas estações meteorológicas de Figueira de Castelo Rodrigo ( $40^{\circ} 52^{\prime} \mathrm{N}$, $6^{\circ} 54^{\prime}$ W e $635 \mathrm{~m}$ ), do Instituto Português do Mar e da Atmosfera (IPMA), e Bragança $\left(41^{\circ} 48^{\prime} \mathrm{N}, 6^{\circ} 44^{\prime}\right.$ W e $691 \mathrm{~m}$ ), cuja informação se encontra disponível, e de modo gratuito, em http://www.tutiempo.net/. 0 recurso a esta última estação deve-se à falta de informação, para alguns dos anos estudados, na estação de Figueira de Castelo Rodrigo. A opção sobre esta estação recaiu depois de se verificar as fortes correlações entre os dados obtidos para a temperatura e a precipitação, num conjunto de anos, com dados em comum em ambas as estações.

Para além da média da temperatura do ar, analisámos, também, o comportamento das médias da temperatura máxima e das temperaturas mínimas mensais, no intuito de perceber qual destas três variáveis exerce maior influência na qualidade vitivinícola da sub-região de Castelo Rodrigo. Para além das variáveis climáticas referidas foram determinados índices bioclimáticos complementares, determinados em função dos principais estádios de desenvolvimento do ciclo vegetativo da videira (TONIETTO \& CARNONNEAU, 1999), os quais se sintetizam na sequência.

\section{Índice Heliotérmico}

Através do índice heliotérmico (IS) é possível estimar o potencial térmico de uma região vitivinícola, tendo em conta a latitude. É calculado para os meses em que se dá o crescimento e desenvolvimento da videira (Abril a Setembro). Os resultados são obtidos em graus-dia ( ${ }^{\circ} \mathrm{C}$ dia ou GD). A acumulação de graus-dia é efetiva a partir do momento em que seja atingido o chamado "zero vegetativo", correspondendo este a cerca de $10^{\circ} \mathrm{C}$ (RoBerto et al., 2005, cit. em MACHADO, 2010). 0 cálculo do índice heliotérmico é realizado para a temperatura-base de $10^{\circ} \mathrm{C}$, a partir dos valores médios mensais da temperatura do ar, sendo efetuado a partir da seguinte equação:

$$
I H=\sum_{1 A b r}^{30 S e t} \frac{[T-10]-[T x-10]}{2} k
$$

Sendo que:

$I H=$ Total de graus-dia acumulado no período entre 1 de Abril e 30 de Setembro ( ${ }^{\circ} \mathrm{C}$ ou GD);
$T=$ Temperatura média do $\operatorname{ar}\left({ }^{\circ} \mathrm{C}\right)$;

$T \mathcal{X}=$ Temperatura máxima do $\operatorname{ar}\left({ }^{\circ} \mathrm{C}\right)$;

$k$ = Coeficiente de duração do dia, varia entre 1,02 e 1,06 entre $40^{\circ}$ e $50^{\circ}$ de latitude.

O Quadro I sistematiza os resultados para a interpretação das classes do clima, segundo o Índice heliotérmico, o qual é estabelecido a partir de uma escala que varia entre o muito frio e quente.

Quadro I

Classificação segundo o Índice Heliotérmico

\begin{tabular}{|c|c|c|}
\hline Classe do Clima & Sigla & Intervalo de Classe (GD) \\
\hline Muito Frio & $\mathrm{IH}_{1}$ & $\mathrm{IH} \leq 1500$ \\
\hline Frio & $\mathrm{IH}_{2}$ & $1500<\mathrm{IH} \leq 1800$ \\
\hline Temperado & $\mathrm{IH}_{3}$ & $1800<\mathrm{IH} \leq 2100$ \\
\hline Temperado Quente & $\mathrm{IH}_{4}$ & $2100<\mathrm{IH} \leq 2400$ \\
\hline Quente & $\mathrm{IH}_{5}$ & $2400<\mathrm{IH} \leq 3000$ \\
\hline
\end{tabular}

Fonte: Adaptado de Tonietto e Carbonneau, 1999.

\section{Índice de Frio Noturno}

O índice de frio noturno (IF) analisa as condições térmicas noturnas durante o período de maturação das uvas. 0 índice de frio noturno é calculado apenas para o mês de Setembro, pois é este mês que corresponde à fase de maturação das uvas. Caso as temperaturas mínimas noturnas durante o mês de Setembro alcancem valores superiores a $12^{\circ} \mathrm{C}$, a maturação das uvas prolonga-se também durante a noite (SANTOS et al. s.d., cit. em MACHADO, 2010). O valor do índice de frio noturno é alcançado através da seguinte equação:

$\mathrm{IF}=\mathrm{Tn}_{\mathrm{q}}$

Sendo que: $\mathrm{Tn}_{9}=$ Temperatura média do $\operatorname{ar}\left({ }^{\circ} \mathrm{C}\right)$ no mês de Setembro (hemisfério Norte).

O Quadro II indica os resultados para a interpretação das classes do clima, segundo o índice de frio noturno, o qual deve ser classificado a partir de uma escala que varia entre clima de noites quentes e clima de noites muito frias.

Quadro II

Classificação segundo o Índice de Frio Noturno

\begin{tabular}{|c|c|c|}
\hline Classe do Clima & Sigla & Intervalo de Classe $\left({ }^{\circ} \mathrm{C}\right)$ \\
\hline Noites Quentes & $\mathrm{IF}_{1}$ & $>18$ \\
\hline Noites Temperadas & $\mathrm{IF}_{2}$ & $>14 \leq 18$ \\
\hline Noites Frias & $\mathrm{IF}_{3}$ & $>12 \leq 14$ \\
\hline Noites Muito Frias & $\mathrm{IF}_{4}$ & $\leq 12$ \\
\hline
\end{tabular}

Fonte: Adaptado de Tonietto e Carbonneau, 1999.

\section{Índice Branas, Bemon e Lavadoux - BBL}

0 índice BBL permite-nos compreender a influência que a temperatura e precipitação exercem sobre a qualidade das uvas e do vinho (LORENZO et al., 2012). Este índice tem em consideração a soma das temperaturas médias mensais $\left({ }^{\circ} \mathrm{C}\right)$ e o total de precipitação mensal $(\mathrm{mm})$, para o período de tempo compreendido entre os meses de Abril a Agosto. O cálculo do índice BBL fornece-nos um limite superior, 
a partir do qual se verifica uma elevada probabilidade da vinha ser atacada pelo míldio. Este limite é alcançado sempre que sejam verificados valores do índice $\mathrm{BBL}$ superiores a $5150\left({ }^{\circ} \mathrm{C} . \mathrm{mm}\right)$ (EVAG, s.d.). $\mathrm{O}$ índice BBL é calculado a partir da seguinte equação:

$$
I B B L=\sum_{1 \mathrm{Abr}}^{31 \text { Ago }} T P
$$

Sendo que:

$I B B L=$ Soma da temperatura média mensal $\left({ }^{\circ} \mathrm{C}\right)$ vezes a soma da precipitação total mensal $(\mathrm{mm})$ entre 1 de Abril e 31 de Agosto;

$$
\begin{aligned}
& T=\text { Temperatura média mensal }\left({ }^{\circ} \mathrm{C}\right) ; \\
& P=\text { Total de precipitação }(\mathrm{mm}) .
\end{aligned}
$$

Para analisar as tendências de evolução (positiva, negativa ou nula) da qualidade dos mostos, das variáveis climáticas e dos índices climáticos vitícolas definidos, assim como para a examinar o grau de inter-relação entre a variável dependente (qualidade dos mostos) e as variáveis independentes, aplicou-se o coeficiente de correlação de Pearson. 0 coeficiente de Pearson é bastante vulgar na avaliação de relações lineares entre variáveis quantitativas (MATOS, 1995). Este coeficiente pode variar de $-1 \mathrm{a}+1$, revelando a intensidade da relação linear entre as duas variáveis, sendo que o coeficiente 1 indica uma correlação linear positiva perfeita. Quanto mais próximo de 1 for o valor do coeficiente, maior associação assume a relação entre variáveis. Se obtivermos uma correlação positiva $(0<r<1)$, as duas variáveis têm tendência a aumentar ou diminuir simultaneamente, sendo diretamente relacionadas entre si. $\mathrm{Na}$ análise dos dados utilizou-se o programa estatístico SPSS e na interpretação dos resultados foram tidos em conta intervalos de confiança superiores a $95 \%$.

\section{Resultados e discussão}

\subsection{Evolução das variáveis e índices climáticos na sub-região de Castelo Rodrigo (1992-2012)}

De acordo com os resultados obtidos através da análise ao comportamento das temperaturas, estudadas para o período de tempo analisado, é notória a tendência positiva, ou seja de aumento das temperaturas, em particular da média e da máxima média mensais (Figura 4). Devemos salientar que foi no ano de 2006 que se verificaram as temperaturas mais elevadas, em todas as variáveis consideradas. Já as temperaturas mais baixas da sub-região, registaram-se no ano de 1993. A tendência para o aumento das temperaturas, na sub-região de Castelo Rodrigo, revelou-se mais significativa na temperatura máxima média $(r=0,607$, sig. $=0,004)$. A temperatura média registou de igual modo, embora menos importante, um aumento estatisticamente significativo $(r=0,491$; sig. $=0,024)$. A temperatura mínima média foi a variável que registou o menor acréscimo, não revelando qualquer significado estatístico.

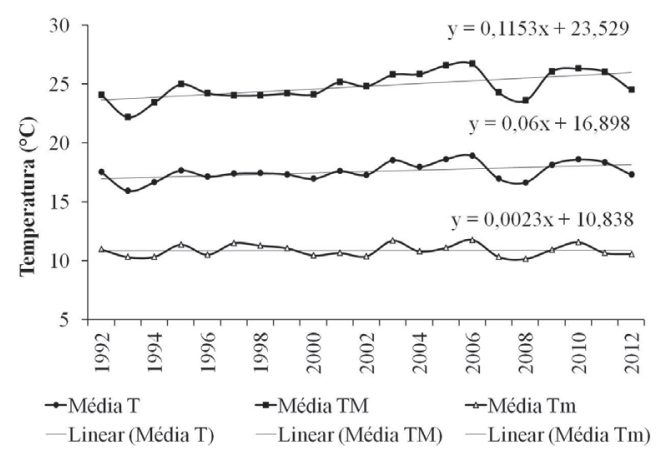

Figura 4

Evolução das temperaturas médias (T), máxima média (TM) e mínima média (Tm), entre os meses de Abril e Setembro, desde 1992 a 2012. Fonte: Elaborado a partir de dados disponíveis no Instituto Português do Mar e da Atmosfera e em http://www.tutiempo.net/

Ao contrário dos resultados obtidos para as temperaturas da sub-região, verifica-se uma tendência negativa nos quantitativos de precipitação assinalados, no período de tempo analisado $(r=-0,594$; sig. $=0,005)$ (Figura 5 ). Os anos que registaram os maiores quantitativos de precipitação foram 1993, 1998 e 1999, ultrapassando os $300 \mathrm{~mm}$ de precipitação entre os meses de Abril a Setembro. Por outro lado, os quantitativos de precipitação mais baixos foram assinalados nos anos de 2004, 2005 e 2009.

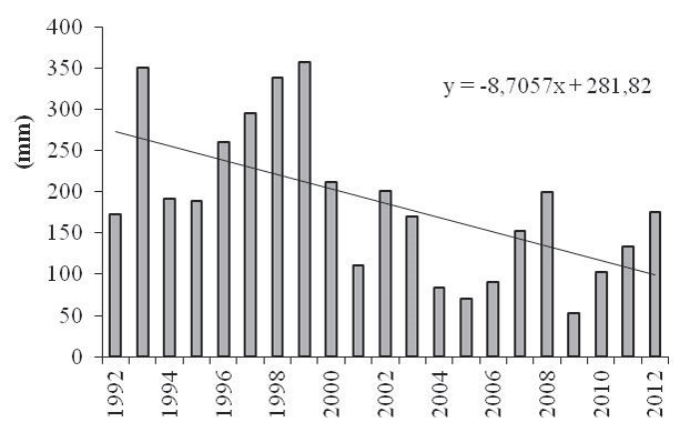

Figura 5

Evolução dos quantitativos de precipitação, entre os meses de Abril e Setembro, desde 1992 a 2012.

Fonte: Elaborado a partir de dados disponíveis no IPMA e em http:// www.tutiempo.net/

\section{Índice Heliotérmico}

Os valores do índice heliotérmico $(\mathrm{IH})$ revelaram uma tendência positiva significativa $(r=0,477$; sig. $=0,029)$, o que significa que se tem vindo a assistir a um aumento de calor acumulado (cerca de $100 \mathrm{GD}$ ) ao longo do ciclo vegetativo da videira (Figura 6). 
Os anos mais críticos foram 1993, que registou o valor mais baixo de todos (1421 GD), sendo também o ano em que se verificaram as temperaturas mais baixas de todo o período de tempo analisado; 1994 com 1486 graus-dia acumulados no ciclo vegetativo da videira e, por fim, o ano de 2008 que fugiu um pouco à regra da tendência assinalada. Este episódio de fraca acumulação de calor prendeu-se com o facto de ser um ano em que a média das temperaturas mínimas se revelou mais baixa. Os anos em que se constatou maior acumulação de graus-dia foram: 2006, com 1685 GD, que correspondeu ao ano em que se assistiu às temperaturas mais elevadas dos vinte e um anos analisados; 2005, que contou com 1659 GD, e 2010, onde foram registados 1657 GD.

Os valores do índice heliotérmico variaram entre duas classes distintas: muito frio $\left(\mathrm{IH}_{1}\right)$ e frio $\left(\mathrm{IH}_{2}\right)$. A primeira classe do índice heliotérmico, muito frio $\left(\mathrm{IH}_{1}\right)$, foi assinalada apenas em três dos vinte e um anos analisados (1993,1994 e 2008). Perante estas condições heliotérmicas somente as castas precoces podem atingir a maturação adequada, em particular as castas brancas. Na segunda classe do índice, frio $\left(\mathrm{IH}_{1}\right)$, integraram-se os restantes anos estudados. Na classe do clima frio o potencial heliotérmico permite que uma vasta gama de castas, quer brancas ou tintas, atinjam a maturação (Tonietto \& Carbonneau, 2000).

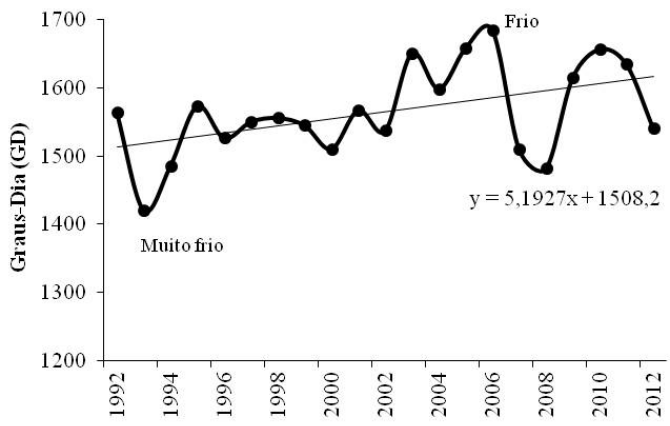

Figura 6

Índice heliotérmico entre os meses de Abril e Setembro.

Fonte: Elaborado a partir de dados disponíveis no Instituto Português do Mar e da Atmosfera e em http://www.tutiempo.net/

\section{Índice de Frio Noturno}

0 índice de frio noturno apesar de revelar uma tendência de positiva $(r=0,1376)$, o respetivo significado estatístico situa-se ao nível de 0,1 . Quer isto dizer, que o acréscimo das temperaturas mínimas, durante o mês de Setembro, não revela significado estatístico (Figura 7). Os valores mais baixos do índice de frio noturno corresponderam aos anos de 1993 $\left(9,5^{\circ} \mathrm{C}\right), 1994\left(10,2^{\circ} \mathrm{C}\right)$ e $1996\left(10,1^{\circ} \mathrm{C}\right)$. Em contrapartida, os valores mais elevados foram alcançados nos anos de $1997\left(13,5^{\circ} \mathrm{C}\right), 2003\left(13^{\circ} \mathrm{C}\right)$ e $2006\left(13,1^{\circ} \mathrm{C}\right)$.

Os resultados obtidos para o índice de frio noturno, calculado para o mês de Setembro, variaram entre duas classes: noites frias $\left(\mathrm{IF}_{3}\right)$ e noites muito frias $\left(\mathrm{IF}_{4}\right)$. Na classe do clima de noites frias $\left(\mathrm{IF}_{3}\right)$, a maturação das uvas ocorreu em condições que podem ser consideradas um pouco adversas, dependendo da precocidade das diversas castas. Na classe do clima de noites muito frias $\left(\mathrm{IF}_{4}\right)$, verificaram-se condições nitotérmicas baixas.

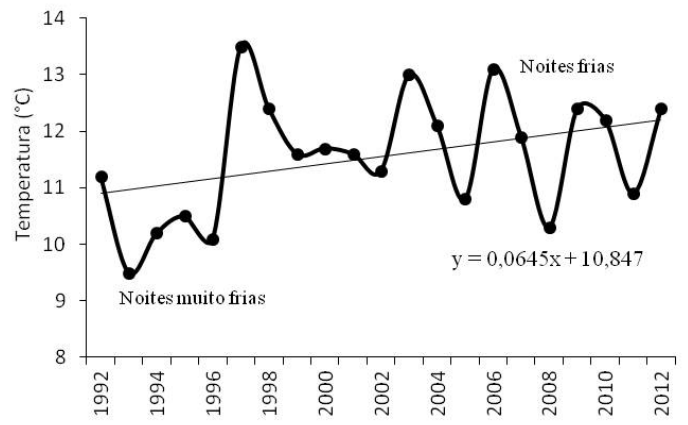

Figura 7: Índice de frio noturno no mês de Setembro.

Fonte: Elaborado a partir de dados disponíveis no Instituto Português do Mar e da Atmosfera e em http://www.tutiempo.net/

\section{Índice Branas, Bemon e Lavadoux - BBL}

Os valores do índice BBL manifestaram uma tendência de decréscimo significativa $(r=-0,548$; sig. $=0,010$ ), a qual se relaciona com a redução da precipitação e aumento das temperaturas, assinaladas em igual período (Figura 8). Os anos de 1993, 1997 e 1998 revelaram ser os mais críticos para o aparecimento de míldio na videira, isto é, foram os anos em que se verificaram os maiores valores do índice BBL: 21678, 21300 e 22150, respetivamente. Perante os resultados observados, podemos afirmar que grosso modo a sub-região esteve em risco ou, foi mesmo atacada pelo míldio. 2005 e 2009 foram os anos em que o índice BBL obteve os valores mais baixos, 3719 e 4269 respetivamente, correspondendo aos anos em que ocorreram os menores quantitativos de precipitação. De acordo com o limite estabelecido para o despoletar do míldio, estes anos não evidenciaram qualquer risco para a videira.

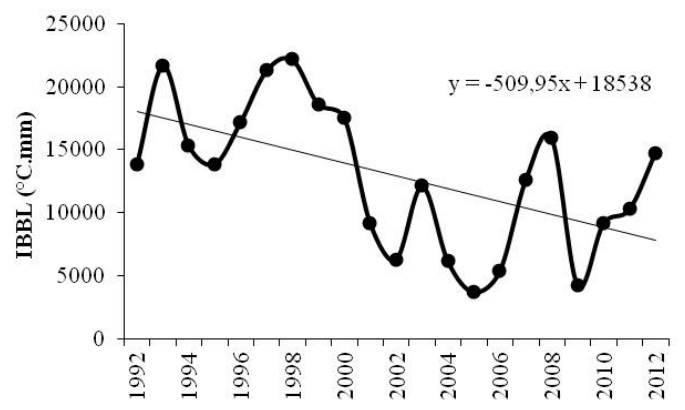

Figura 8

Índice BBL entre os meses de Abril e Agosto, desde 1992 a 2012. Fonte: Elaborado a partir de dados disponíveis no Instituto Português do Mar e da Atmosfera e em http: //www.tutiempo.net/ 


\subsection{Evolução da qualidade vitivinícola entre 1992 e 2012}

A tendência obtida no comportamento do grau médio do mosto, entre 1992 e 2012, revela-se positiva ( $r=0,494$; sig. $=0,023$ ), o que nos permite concluir que a qualidade vitivinícola tem vindo a aumentar ao longo dos últimos anos, verificando-se um incremento de cerca de $1^{\circ}$ durante os vinte e um anos estudados (Figura 9).

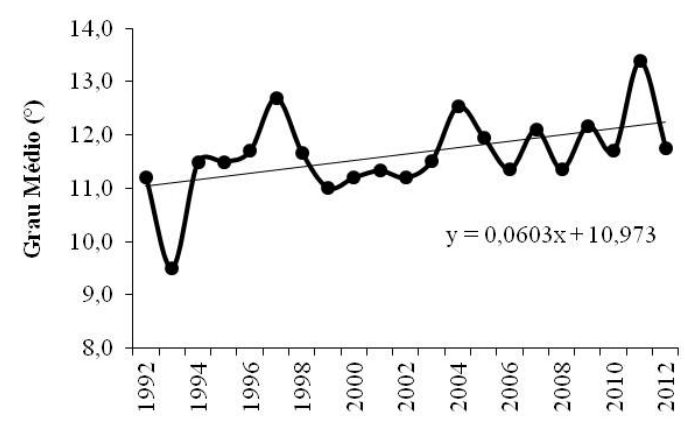

Figura 9

Evolução da qualidade vitivinícola na sub-região de Castelo Rodrigo entre 1992 e 2012

Fonte: Elaborado a partir de dados disponibilizados pela Adega Cooperativa de Figueira de Castelo Rodrigo.

Nesse período, o grau médio mais baixo foi registado em $1993\left(9,5^{\circ}\right)$, a que se segue o de 1999 $\left(11^{\circ}\right)$. Por seu turno, os anos de 1997, 2004 e 2011 registaram os valores mais elevados de grau médio, $12,7^{\circ}, 12,5^{\circ}$ e $13,4^{\circ}$ respetivamente.

Considerámos as castas Uva de Mesa, Touriga, Tinta Roriz e Alfrocheiro, para uma análise mais pormenorizada daquele que foi o seu comportamento ao longo dos anos, em que as mesmas foram entregues, de forma separada, na cooperativa da sub-região (Figura 10). Assim, na Uva de Mesa verificou-se uma tendência de acréscimo em termos de teor de álcool $(r=0,608$, sig. $=0,004)$, a rondar os dois graus. Os anos em que foram registados os valores de grau mais baixo desta casta foram $1993\left(7,6^{\circ}\right), 1998\left(9,8^{\circ}\right)$ e $1999\left(9,3^{\circ}\right)$. Pelo contrário, em 1997, 2007 e 2011, foram obtidos os valores mais elevados do grau médio: $12,7^{\circ} ; 12,8^{\circ}$ e $13,7^{\circ}$ respetivamente.

A casta Touriga revelou, igualmente, uma tendência positiva muito significativa $(r=0,716$; sig. $=0,004)$, o que representa uma subida gradual do grau médio desta casta, superior a $2^{\circ}$. Os valores inferiores do grau médio foram atingidos nos anos de $2000\left(10,2^{\circ}\right), 2001\left(10,1^{\circ}\right)$ e $2003\left(10,2^{\circ}\right)$. Pelo contrário, os melhores anos em termos de qualidade foram 2007, 2009 e 2011, onde foram obtidos resultados superiores em termos de grau médio: $12,4^{\circ} ; 12,1^{\circ}$ e $13,3^{\circ}$ respetivamente.

A casta Tinta Roriz também revelou uma tendência positiva na sua qualidade, apesar do respetivo acréscimo não apresentar significado estatístico $(r=0,404$; sig. $=0,152)$. Os anos em que foram registados os valores mais reduzidos do grau médio foram os $2001\left(10,2^{\circ}\right) ; 2002\left(10,5^{\circ}\right)$
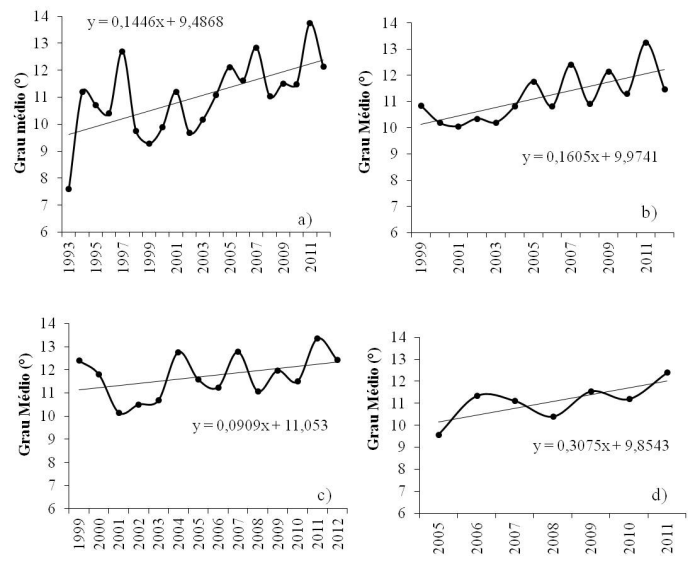

Figura 10

Evolução do grau médio: a) casta Uva de Mesa; b) casta Touriga; c) casta Tinta Roriz; d) casta Alfrocheiro

Fonte: Elaborado a partir de dados disponibilizados pela Adega Cooperativa de Figueira de Castelo Rodrigo;

e $2003\left(10,7^{\circ}\right)$. Já os anos que se revelaram superiores na qualidade da casta em questão foram: $2004\left(12,8^{\circ}\right)$, $2007\left(12,8^{\circ}\right)$ e, finalmente, o ano de $2011\left(13,4^{\circ}\right)$.

O Alfrocheiro foi, de todas as castas estudadas, a que maior acréscimo apresentou, em termos de grau médio. A tendência apresentada pela casta revelou-se positiva, $(r=0,756$; sig. $=0,049)$, ditando uma evolução de cerca de $2^{\circ}$ no período de tempo analisado. Os anos de 2005, 2007 e 2008 surgem como os mais adversos para a qualidade desta casta, apresentando $9,6^{\circ} ; 11,1^{\circ}$ e $10,4^{\circ}$ respetivamente. Já os anos que se revelaram mais propícios foram: 2006 $\left(11,3^{\circ}\right) ; 2009\left(11,6^{\circ}\right)$ e $2011\left(12,4^{\circ}\right)$.

\subsection{Influência climática na qualidade vitivinícola}

Com o objetivo de analisar a influência das condições climáticas na qualidade dos mostos, procedemos ao cálculo do coeficiente de correlação de Pearson entre esta e as diversas variáveis climáticas. Das correlações realizadas entre a qualidade e as temperaturas médias, máximas médias e mínimas médias mensais, obtivemos relações positivas, com significado estatístico, entre a temperatura média $(r=0,524$; sig $=0,015)$ e a máxima média $(r=0,529 ; p=0,014)$. Com a temperatura mínima média a correlação é positiva $(r=$ 0,$185 ;$ sig=0,423), mas sem significado estatístico. Podemos, deste modo, afirmar que quanto mais elevadas forem as temperaturas, médias e máximas mensais, maior grau será alcançado nos mostos (Figura 11).

A correlação obtida entre a qualidade e a precipitação manifestou-se negativa $(r=-0,446$; sig. $=0,043$ ), indiciando que a ocorrência de maiores quantitativos de chuva pode deter um efeito negativo no grau dos mostos (Figura 12). As correlações observadas entre a qualidade e os índices climáticos apresentam-se positivas com os índices térmicos (heliotérmico: $r=0,503$; e de frio noturno: $r=0,398$ ) e 


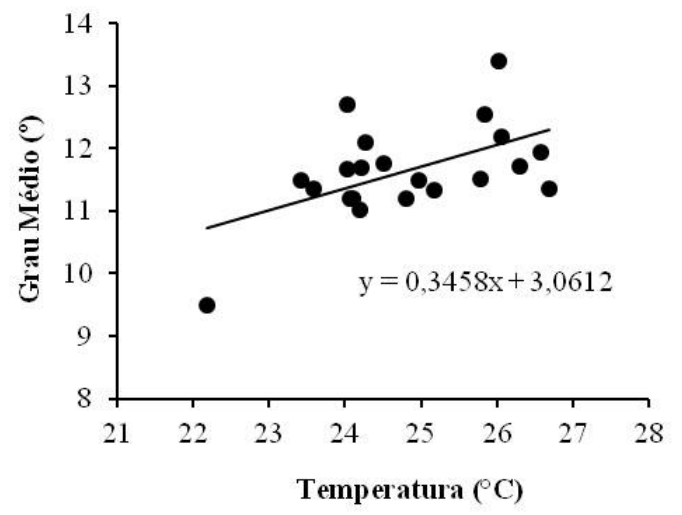

Figura 11

Correlação de Pearson entre temperatura e a qualidade vitivinícola da sub-região de Castelo Rodrigo entre 1992 e 2012;

Fonte: Elaborado a partir de dados disponibilizados pela Adega Cooperativa de Figueira de Castelo Rodrigo, no Instituto Português do Mar e da Atmosfera e em http://www.tutiempo.net/

negativa com o índice que se relaciona com a humidade, BBL $(r=0,330)$, dando, mais uma vez, ênfase à forte relação que os elementos climáticos (temperatura e precipitação) exercem na qualidade vitivinícola.

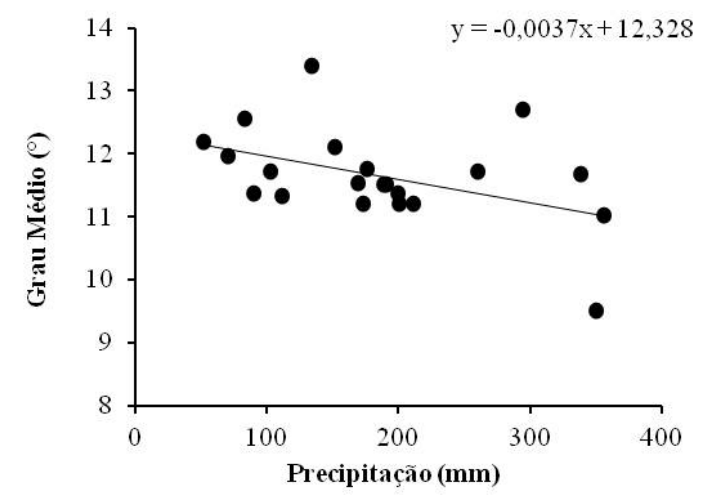

Figura 12

Correlação de Pearson entre a qualidade vitivinícola e a precipitação da sub-região de Castelo Rodrigo entre 1992 e 2012

Fonte: Elaborado a partir de dados disponibilizados pela Adega Cooperativa de Figueira de Castelo Rodrigo, no Instituto Português do Mar e da Atmosfera e em TuTiempo.

\subsection{Influência climática no início de colheita}

Confirmado o aumento dos valores de temperatura, a maturação das uvas deverá ocorrer antecipadamente, graças à maior acumulação de GD, o que irá, decerto, influenciar a data de início da colheita. Assim, usando como variáveis o tempo (evolução do número de anos) e a data do início da colheita entre os anos de 1992 e 2012, verificámos que a mesma se estendeu entre os dias 13 de Setembro e 4 de Outubro. 0 coeficiente apurado entre ambas as variáveis mostra uma relação negativa, significativa $(r=-0,497)$ (Figura 13). Perante os resultados obtidos pode dizer- -se que à medida que os anos foram passando a data do início da colheita tem vindo a ser antecipada corroborando a ideia anteriormente defendida, de que a evolução climática também influenciou a data em que se iniciam as vindimas.

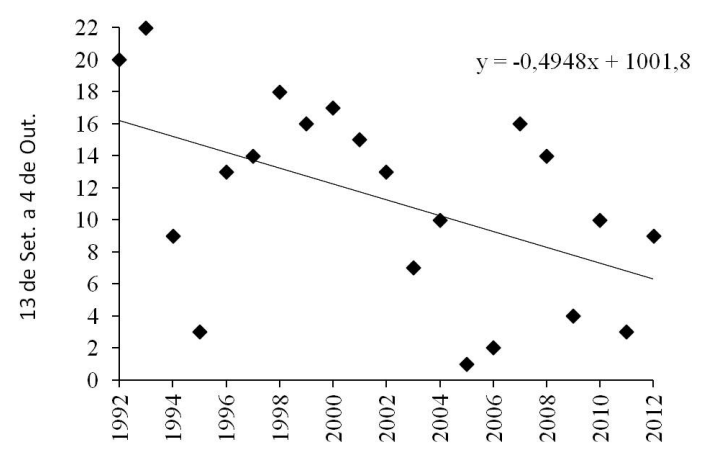

Figura 13

Evolução da data de início da colheita na sub-região de Castelo Ro drigo entre 1992 e 2012

Fonte: Elaborado a partir de dados disponibilizados pela Adega Cooperativa de Figueira de Castelo Rodrigo.

\subsection{Outros fatores condicionantes da qualidade vitivinícola}

A qualidade vitivinícola é influenciada por vários fatores, como por exemplo tipo de solo onde as videiras se encontram instaladas, apresentando diferentes características físicas, químicas e biológicas. No entanto, não nos foi possível obter informação quantitativa, isto é sobre as características dos vinhos em função das diferentes unidades pedológicas presentes na região.

Outra condicionante do grau adquirido nos mostos produzidos, diz respeito às castas selecionadas, pois como verificámos anteriormente, umas possuem melhores condições organoléticas do que outras. A média do grau alcançado por casta, para o período de tempo correspondente à análise, apresentou-se distinto: Uvas de Mesa $\left(11^{\circ}\right)$, Touriga $\left(11,2^{\circ}\right)$, Tinta Roriz $\left(11,7^{\circ}\right)$, Síria $\left(12^{\circ}\right)$ e Alfrocheiro $\left(11,1^{\circ}\right)$. Podemos, então, concluir que a casta Síria e Tinta Roriz produzem mostos de melhor qualidade que as restantes castas.

Outro dos fatores que explica a variação da qualidade dos mostos prende-se com a hora do dia em que as uvas são colhidas. Com efeito, assistimos à colheita das uvas, numa vinha com a casta Síria. Assim, as uvas colhidas durante o período da manhã ditaram menor grau nos mostos, registado aquando da sua entrega na cooperativa de Figueira de Castelo Rodrigo (Figura 14, em cima).

Em contrapartida, as uvas colhidas no período da tarde assinalaram um grau mais elevado nos respetivos mostos (Figura 14, em baixo). 0 motivo pela qual se verifica esta diferença de grau, na mesma casta mas em diferentes horas do dia, prende-se com o facto de, no período da manhã, as videiras se 
encontrem orvalhadas devido às baixas temperaturas ocorridas durante a noite, o que conduz a que as uvas colhidas contenham maior humidade, logo menor qualidade $\left(11^{\circ}\right)$, devido à diluição dos açúcares e de outras componentes organoléticas.

Pelo contrário, as uvas colhidas no período da tarde contêm maior acumulação de graus-dia, o que implica maior calor acumulado e, consequentemente, maior qualidade dos mostos $\left(13,3^{\circ}\right)$.
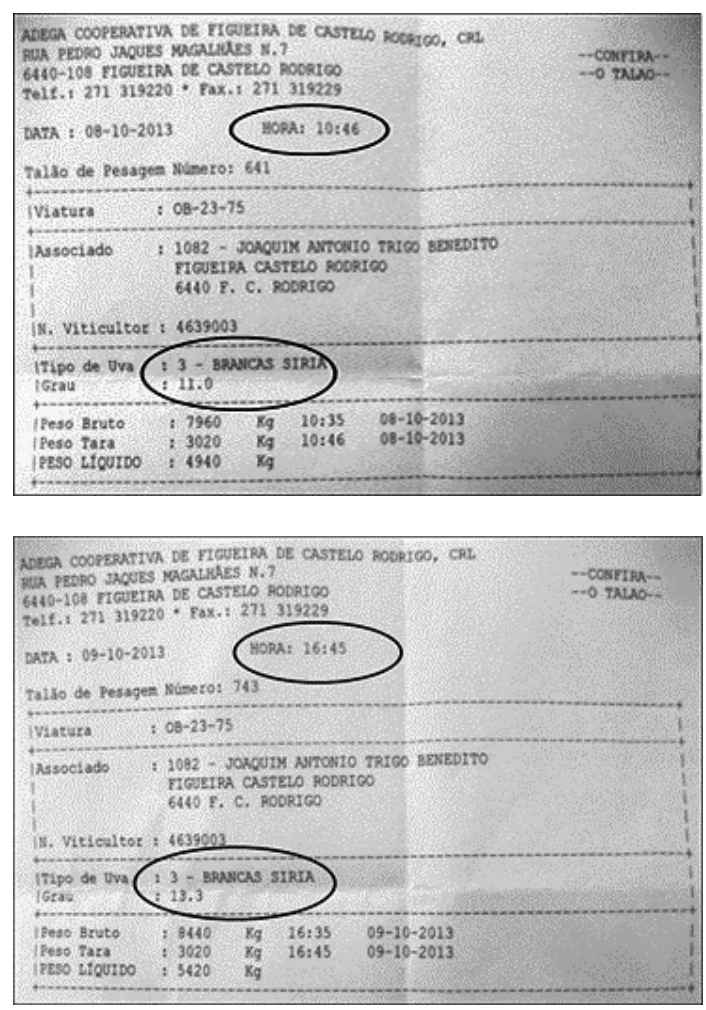

Figura 14

Grau médio da casta Síria atingido nas uvas colhidas no período da manhã (10:46h) e no período da tarde $(16.45 \mathrm{~h})$ na Sub-região de Castelo Rodrigo.

\section{Conclusão}

A qualidade vitivinícola da sub-região em estudo revelou uma evolução positiva, em consequência do aumento do grau médio dos mostos, em cerca de $1^{\circ}$, produzidos nestas últimas 2 décadas. Este incremento foi registado em algumas das castas de qualidade superior, recomendadas para a sub-região. 0 Alfrocheiro e Touriga foram, entre as analisadas, as que mostraram maior incremento em termos de grau.

As tendências de evolução assinaladas pelas variáveis climáticas analisadas contribuíram para este incremento na qualidade dos mostos. 0 aumento da temperatura e a diminuição da precipitação traduziram-se, assim, numa maior acumulação de calor no decurso do ciclo vegetativo da videira, e a probabilidade da área de estudo ser atacada pelo míldio também decresceu.
As tendências manifestadas por estas duas variáveis contribuíram, igualmente, para a antecipação da maturação das uvas, o que implica que as vindimas se realizem cada vez mais cedo. Todavia, outras variáveis deverão ser ponderadas na qualidade final dos mostos, nomeadamente as que se relacionam com os tipos de castas, caraterísticas dos solos e o período do dia em que a colheita é efetuada.

\section{Referências bibliográficas}

Lorenzo, M. N.; Taboada, J. J.; Lorenzo, J. F. e Ramos, A. M. (2012) - "Influence of climate on grape production and wine quality in the Rías Baixas, north- western Spain”. Reg Environ Change, Springer- Verlag, Berlin Heidelber, 12 p.

MACHADO, C. (2010) - Vulnerabilidade da Região Demarcada do Douro às alterações climáticas e efeitos sobre o ciclo vegetativo da videira. O caso do Moscatel Galego. Dissertação de Mestrado em Planeamento e Gestão do Território/Geografia apresentada ao Instituto de Ciências Sociais da Universidade do Minho, 81 p.

Matos, M. (1995) - Manual Operacional para a Regressão Linear. Faculdade de Engenharia da Universidade do Porto, 26 p.

Monteiro, J. E. B. de A.; Tonietto, J.; Taffarel , J. C. e Zanus, M. C. (2012) - "Condições meteorológicas e a sua influência na vindima de 2012 nas regiões vitivinícolas sul brasileiras". Comunicado Técnico $n^{\circ}$ 122, Bento Gonçalves, RS, 12 p.

Nilson, T. (2010) - Influência do clima sobre os estádios fenológicos da videira e sobre a qualidade e quantidade da produção. Trabalho de conclusão de Curso Superior apresentado ao Instituto Federal de Educação, Ciência e Tecnologia do Rio Grande do Sul - Campus Bento Gonçalves, 49 p.

Nunes, A. e Vieira, A. (1999) - "A influência do clima na produção vitivinícola anual”. Atas do I/ Colóquio de Geografia de Coimbra, n. ${ }^{\circ}$ Especial de "Cadernos de Geografia”, pp. 207-211.

Oliveira, J. (2000) - Aromas varietais e de fermentação determinantes da tipicidade das castas Loureiro e Alvarinho. Dissertação de Doutoramento em Engenharia Biológica apresentada à Escola de Engenharia da Universidade do Minho, $217 \mathrm{p}$.

Rivas-Martìnez, S. (1996) - Geobotánica y bioclimatologia. Discurso del Acto de Investidura de Doctor "Honoris Causa" de la Universidad de Granada. 98 p.

Tonietto, J. e Carbonneau, A. (1999) - “Análise mundial do clima das regiões vitícolas e de sua influência sobre a tipicidade dos vinhos: a posição da viticultura brasileira comparada a 100 regiões em 30 países". In: IX Congresso Brasileiro de Viticultura e Enologia, Bento Gonçalves, Anais. Bento Gonçalves, Embrapa Uva Vinho, pp. 75-90. 